\title{
Biomass estimates of freshwater zooplankton from length-carbon regression equations
}

\author{
Marina MANCA* and Patrizia COMOLI \\ C.N.R. Istituto Italiano di Idrobiologia - 28922 Verbania Pallanza, Italy \\ *e-mail corresponding author: m.manca@iii.to.cnr.it
}

\begin{abstract}
We present length/carbon regression equations of zooplankton species collected from Lake Maggiore (N. Italy) during 1992. The results are discussed in terms of the environmental factors, e.g. food availability, predation, controlling biomass production of particle-feeders and predators in the pelagic system of lakes. The marked seasonality in the length-standardized carbon content of Daphnia, and its time-specific trend suggest that from spring onward food availability for Daphnia population may be regarded as a simple decay function. Seasonality does not affect the carbon content/unit length of the two predator Cladocera Leptodora kindtii and Bythotrephes longimanus. Predation is probably the most important regulating factor for the seasonal dynamics of their carbon biomass. The existence of a constant factor to convert the diameter of Conochilus colonies into carbon seems reasonable for an organism whose population comes on quickly and just as quickly disappears.
\end{abstract}

Key words: carbon, body length, zooplankton

\section{INTRODUCTION}

Carbon biomass estimates of zooplankters are essential for the evaluation of secondary production and the construction of models on energy and carbon flux through the zooplankton (Culver \& De Mott 1978; Serruya et al. 1980). The use of a simple factor to convert from numbers to biomass is biased by the indeterminate growth of cladocerans and the numerous instars of copepods. The relative abundance of different stages and sizes of organisms change during the season, as do the average sizes of mature organisms (Culver 1980). In populations with continuous recruitment, the estimated relation between the size and carbon mass of individuals changes both with the size structure of the population and with the season, reflecting different nutritional conditions. If known, seasonal-specific equations allow an accurate reconstruction of changes in biomass, even in the long-term, whenever length measurements are available.

Among the different methods for estimating biomass, the analysis of dry weight and carbon content in live organisms has been recommended as the most appropriate (Boersma \& Vijverberg 1994). In this paper we present the length/carbon regression equations resulting from the analysis of live zooplankton specimen collected from Lake Maggiore (N. Italy) during 1992.

\section{MATERIALS AND METHODS}

From March to November 1992 we analyzed the carbon (Carlo Erba 1106 elemental analyzer) of live individuals of known length and dry weight, selected from zooplankton samples collected from Lake Maggiore (upper $50 \mathrm{~m}$, Clarke-Bumpus plankton samplers, 76 and $126 \mu \mathrm{m}$ nets) at $\mathrm{ca}$ monthly intervals. From the samples, which represented the content of at least 1000 litre of lake water, we selected specimens of both herbivorous and predacious cladocera, namely Daphnia hyalinagaleata, Bythotrephes longimanus, Leptodora kindtii, as well as of a rotifer species (Conochilus hippocrepis) which has recently increased in numbers in the lake (Manca \& Sonvico 1996). Sorted zooplankters from samples taken throughout the year were analyzed according to Manca et al. (1994, 1997), to account for seasonality.

The selected species covered a wide range of body lengths, from $0.8 \mathrm{~mm}$ (Conochilus colonies, young Daphnia) to $9.7 \mathrm{~mm}$ (Leptodora). Each zooplankter was measured with an ocular micrometer according to its body shape (Fig. 1) (Culver et al. 1985). For Bythotrephes we separated body from spine length, measuring body length from the apex of the head to the base of the spine, barbs excluded (Burkhardt 1994). In the case of Conochilus, we measured the diameter of the spherical colonies (Ruttner-Kolisko 1974). The equation used was in the form:

$$
\text { Ln } C=\ln a+b \ln L
$$

where $a$ and $b$ are fitted constants, $C$ is the weight (carbon, in $\mu \mathrm{g}$ ) and $L$ the body length in $\mathrm{mm}$.

Analysis of variance was performed on each regression to determine whether the slope and the intercept of the line (value of $b$ and $a$, respectively) were significantly different from zero ( $F$-test). In the case of a wide scattering of the data we calculated the parameters of the equations for different periods of the year, using a $t$ - 
test for differences among slopes and for differences among intercepts (two-tailed test at $\mathrm{P}<0.05$ ).

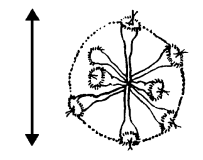

Conochilus

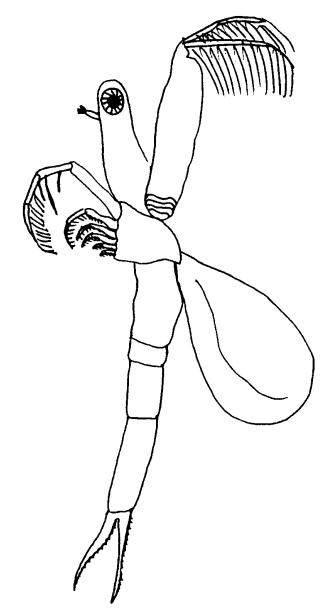

Leptodora

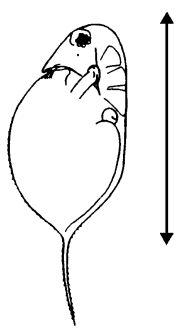

Daphnia

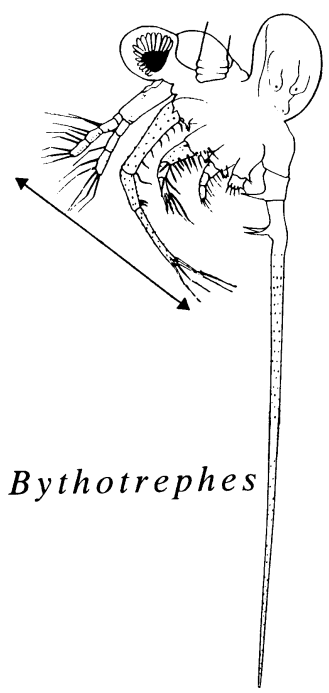

Fig. 1. Method of measuring body length for the different zooplankton taxa.

\section{RESULTS AND DISCUSSION}

There was a marked seasonality in the carbon content per unit length of Daphnia (Manca et al. 1997). As a consequence, the equation for the pooled data (only non-ovigerous females) accounted for only $54 \%$ of the total variance.

The difference between spring and summer data was essentially due to an exponential decrease of the lengthstandardized carbon content from spring onward. The slope of the relation carbon/length was the same for different body length classes so we found that, instead of giving different equations for different periods of the year, a simple adjustment of the elevation of the regression line was sufficient to describe the entire set of data and account for the time trend in the Length Carbon Regression. There was no need to adjust the slope with a product (interaction) term $(\mathrm{d} t \ln L)$. The resulting equation for Daphnia (only non-ovigerous females) was as follows:

$$
\begin{aligned}
\ln C= & 1.830( \pm 0.137)+ \\
& +1.865( \pm 0.198) \ln L-0.0033( \pm 0.0006) t
\end{aligned}
$$

where $C=\mu \mathrm{g} ; L=\mathrm{mm} ; t=$ days $) ; R^{2}=0.76 ; F=46.47 ; N=$ 425; $P<0.001$ (Manca et al. 1997).
The parameters of the time-corrected LCR equation of Daphnia did not change significantly when females with eggs in the first three developmental stages (as described by Green 1956) were included (Manca et al. 1997). We explained this result considering egg deposition up to this stage as a simple transfer of a certain amount of carbon from one compartment of the mother's body (lipid drops) to another (brood chamber, as eggs) (Manca et al. 1994).

The individual carbon content of Leptodora increased exponentially with body length (Fig. 2). A single estimate of the parameters was sufficient to describe the pooled data, obtained during the entire growing season of the population in Lake Maggiore. This means that seasonality is not important for the carbon content of this predacious species, and variations are only due to changes in body length.


Fig. 2. Length/Carbon regression equation of Leptodora kindtii collected from Lake Maggiore (pooled data from June to September). Predicted/observed individual carbon values are also reported.

The equation most satisfactorily fitting the experimental data was as follows:

$$
\ln C=-0.79( \pm 0.20)+2.25( \pm 0.11) \ln L
$$

with $R^{2}=0.91 ; F=389.12 ; N=49 ; P<0.001$.

The slope of the curve is a little more than 2, as commonly reported in literature (Peters 1983). Therefore, the length-standardized carbon content of Leptodora increases linearly with body length. Contrary to Daphnia, no saturation-type effect is observed for this species (Manca et al. 1994). C: dry weight ratio is fairly constant, around 0.41 . 
Carbon content of Bythotrephes is negatively correlated with body length (spine excluded) at a high significant level $(r=0.92 ; P<0.001)$. Spine length does not affect so much the relationship between carbon and body length of Bythotrephes.

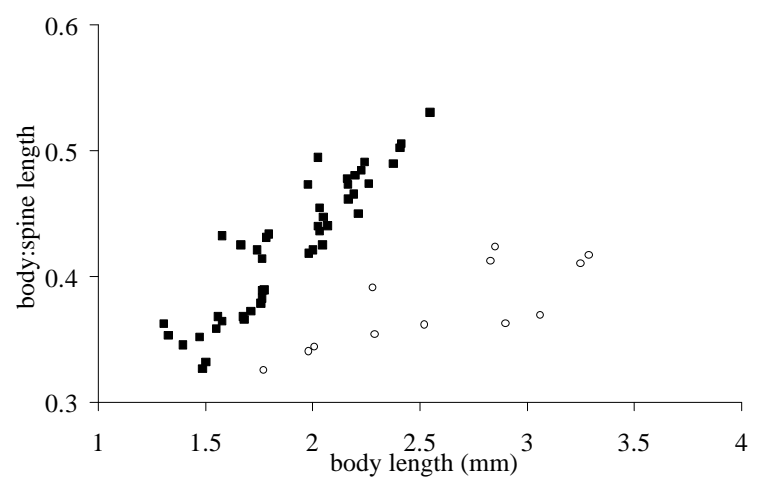

Fig. 3. Relationship between spine and body length in Bythotrephes. Full squares refer to B. longimanus from Lake Maggiore; open circles to $B$. cederstroemi (data from Burkhardt 1994).

The ratio body: spine length $(B: S)$ increases linearly with body length $(B)$ : younger, smaller individuals of Bythotrephes longimanus possess proportionally longer spines than older, larger ones (Fig. 3). A regression equation satisfactorily fits the data, with both slope and intercept of the equation significantly different from zero:

$$
B: S=0.13( \pm 0.02)+0.15( \pm 0.01) B
$$

with $R^{2}=0.84 ; F=229.38 ; N=43 ; P<0.001$. Our data are quite different from those of the congeneric species $B$. cederstroemii (Burkhardt 1994); the data do not overlap and the regression lines would have different slopes (Fig. 3). In fact, the tail spine of B. cederstroemii is markedly longer than that of $B$. longimanus. Carbon content of $B$. longimanus is well correlated with its body length, spine excluded. Although more scattered than in Leptodora, the data obtained at different times of the year are satisfactorily described by a single LCR equation, which accounts for more than 80 per cent of the total variance (Fig. 4). The equation is as follows:

$$
\ln C=1.62( \pm 0.10)+2.12( \pm 0.15) \ln L
$$

with $R^{2}=0.83 ; F=192.98 ; N=47 ; P<0.001$.

As for Leptodora, slope is quite close to 2, indicating a linear increase of the length- standardized carbon content together with body length.

Finally, the carbon content of Conochilus hippocrepis increases linearly with the diameter of the colonies; a constant factor allows the conversion of size into carbon $\left(3 \pm 0.6 \mu \mathrm{gm}^{-1}\right.$, in a range of 0.8-1.4 mm). No significant variation is found with seasonality. Although related to the body length of the oldest individuals, colony size results in an increase in the number of individuals/colony (Manca \& Sonvico 1996). A Conochilus colony has approximately half the carbon content/unit length of a "spring" Daphnia.
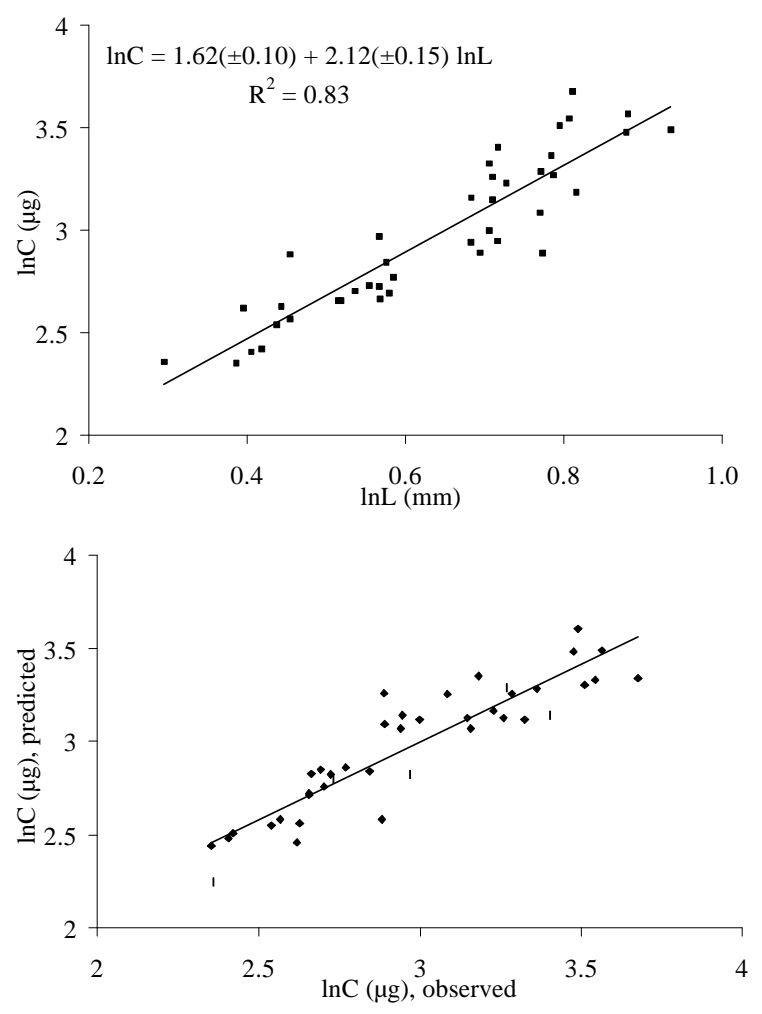

Fig. 4. Length/Carbon regression equation of Bythotrephes longimanus collected from Lake Maggiore (pooled data from March to November). Predicted/observed individual carbon values are also reported.

\section{CONCLUSIONS}

Seasonal variations in the length-standardized carbon content reflect variations in food conditions, which are related to food quality and quantity (Duncan 1985; Manca et al. 1994).

The marked seasonality of the length-standardized carbon content of Daphnia suggests that food conditions are a very important regulating factor for the growth of Daphnia population in Lake Maggiore. Although a seasonal decrease in carbon/unit length is observed in other lakes (Berberovic 1990), the numerical value of parameter c in equation (2) is probably specific to Lake Maggiore, and likely also to the year of the study. However, the type of time-specific trend observed suggests that, from spring onward, food availability for Daphnia population may be represented by a simple decay function. The highest value is found when large individuals of Daphnia are present in low numbers, in an environment rich in food. Spring can be regarded, for Daphnia population, as a very delicate phase, in which the potential is poised for the subsequent development of the population.

The decrease in length-specific carbon content indicates that the transfer of this potential energy into new 
individuals results in an increase in competition. Changes in individual carbon content are also important for organisms that prey on Daphnia. To get the same amount of carbon, a higher number of individuals are required in summer than in spring. Apart from being well explained on a metabolic basis, the saturation-type carbon/body length curve of Daphnia may be regarded as a stabilising mechanism, able to reduce the damage of individual predation on the larger upper size component of the population.

Food conditions do not seem to play an important role for L. kindtii and B. longimanus of Lake Maggiore. These two Cladocera change their diet with the season because different prey are available, although they are selective in their food preferences (Branstrator \& Lehman 1991; Schultz \& Yurista 1996). Indeed, our data suggest that the input of biomass and energy per unit size tends to remain constant, indicating that competition is not an important factor for their populations. Predation is probably the most important regulating factor for the seasonal dynamics of carbon biomass of $L$. kindtii and B. longimanus in Lake Maggiore: it acts on both the density and the size structure of the population. It is not restricted to fish, indeed, as B. longimanus itself is able to capture and eat $L$. kindtii. In Lake Maggiore, the two predators tend to be separated in time and space: $B$. longimanus is a spring and autumn species, while $L$. kindtii is a typical summer taxon. The former is usually most abundant in the epilimnion, while the latter also inhabits deep waters. B. longimanus predation seems to play a role during the late summer phase of decline of the L. kindtii population (Manca, pers. obs.).

While unimportant for carbon, the length of $B$. longimanus spine is considered important for repelling predation by young fish (Barnhisel 1991; Burkhardt 1994; Tatrai et al. 1995). Its inverse relationship with body length suggests that spine elongation is a mechanism to minimize predation pressure on young individuals. Differences in slope of the equations found for $B$. longimanus and B. cederstroemii (Fig. 3) might reflect differences in size of the predator-prey spectra. Classic papers already commented on the relatively small size of B. longimanus specimens from deep, subalpine lakes, (Ishreyt 1938) as well as on their ability to produce eggs before moulting (ovigerous one-pair barbs females), as well as on their incomplete development (lacking of three-barbed individuals).

Finally, the existence of a constant factor to convert diameter of Conochilus colonies into carbon seems reasonable for an organism whose population comes on quickly and just as quickly disappears.

\section{ACKOWLEDGMENTS}

We are very indebted to A.H. Litt and to an anonymous reviewer for commenting on a previous version of the manuscript.

\section{REFERENCES}

Barnhisel, D.R. 1991. The caudal appendage of the cladoceran Bythotrephes cederstroemii as defense against young fish. J. Plankton Res., 13: 529-537.

Berberovic, R. 1990. Elemental composition of two coexisting Daphnia species during the seasonal course of population development in Lake Constance. Oecologia, 84: 340-350.

Boersma, M. \& J. Vijverberg. 1994. The effects of preservation methods on the carbon content of Daphnia. Arch. Hydrobiol., 130: 129-142.

Branstrator, D.K. \& J.T. Lehman. 1991. Invertebrate predation in Lake Michigan: regulation of Bosmina longirostris by Leptodora kindtii. Limnol. Oceanogr., 36: 483-495.

Burkhardt, S. 1994. Seasonal size variation in the predatory cladoceran Bythotrephes cederstroemii in Lake Michigan. Freshwat. Biol., 31: 97-108.

Culver, D.A. 1980. Seasonal variation in the sizes at birth and at first reproduction in Cladocera. In: W.C. Kerfoot (Ed.), The evolution and ecology of zooplankton and ecology of zooplankton communities. A.S.L.O., Spec. Symp., Univ. Press New England, Hanover, NH: 358-366.

Culver, D.A. \& W.R. De Mott. 1978. Production of zooplankton at nearshore stations in lakes Ontario and Erie. Verh. int. Ver. Limnol., 20: 252-256.

Culver, D.A., M.M. Boucherle, D.J. Bean \& J.W. Fletcher. 1985. Biomass of freshwater crustacean zooplankton from length-weight regression. Can. J. Fish. aquat. Sci., 42: 1380-1390.

Duncan, A. 1985. Body carbon in daphnids as an indicator of the food concentration available in the field. Arch. Hydrobiol. Beih., 21: 81-90.

Green, J. 1956. Growth, size and reproduction in Daphnia (Crustacea: Cladocera). Proceedings Zoological Society of London, 126: 173-204.

Ishreyt, G. 1938. Ueber den Bythotrephes subalpiner Seen. Arch. Hydrobiol., 34: 105-129.

Lehman, J.T. \& D. Branstrator. 1995. A model for growth, development, and diet selection by the invertebrate predator Bythotrephes cederstroemii. J. Great Lakes Res., 21: 610619.

Manca, M., T. Spagnuolo \& P. Comoli. 1994. Variations in carbon and nitrogen content with body length of Daphnia hyalina-galeata s.l. from laboratory and field observations. J. Plankton Res., 16: 1303-1314.

Manca, M. \& D. Sonvico. 1996. Seasonal variations in population density and size structure of Conochilus in Lake Maggiore: a biannual study. Mem. Ist. ital. Idrobiol., 54: 97-108.

Manca, M., P. Comoli \& T. Spagnuolo. 1997. Length-specific carbon content of the Daphnia population in a large subalpine lake, Lake Maggiore (Northen Italy): the importance of seasonality. Aquat. Sci., 59: 48-56.

Peters, R.H. 1983. The ecological implications of body size. Cambridge University Press: 329 pp.

Ruttner-Kolisko, A. 1974. Plankton Rotifers. Biology and Taxonomy. Die Binnengewässer, Vol. XXVI Suppl. Part 1: $146 \mathrm{pp}$.

Schultz, K. \& P.M. Yurista. 1995. Diet composition from allozyme analysis in the predatory cladoceran Bythotrephes cederstroemii. Limnol. Oceanogr., 40: 821-826.

Serruya, C., M. Gophen \& U. Pollinger. 1980. Lake Kinneret: carbon flow patterns and ecosystem management. Arch. Hydrobiol., 88: 265-302.

Tatrai, I., G. Giussani, M. Manca \& R. de Bernardi. 1995. An experimental study of Lake Maggiore zooplankton comsumption by bleak (Alburnus alburnus alborella) in different simulated habitats. Mem. Ist. ital. Idrobiol., 53: 7584. 